\title{
Learning Rates for Energy Technologies
}

\section{Alan McDonald}

Leo Schrattenholzer

RR-01-14

December 2001 



\section{Learning Rates for Energy Technologies}

Alan McDonald

Leo Schrattenholzer

RR-01-14

December 2001

Reprinted from Energy Policy 29 (2001) 255-261.

International Institute for Applied Systems Analysis - Schlossplatz 1 - A-2361 Laxenburg - Austria

Tel: (+43 2236) 807 • Fax: (+43 2236) 71313 -E-mail: publications@iiasa.ac.at •Web: www.iiasa.ac.at 
Research Reports, which record research conducted at IIASA, are independently reviewed before publication. Views or opinions expressed herein do not necessarily represent those of the Institute, its National Member Organizations, or other organizations supporting the work.

Reprinted with permission from Energy Policy 29 (2001) 255-261.

Copyright (c) 2001 Elsevier Science

All rights reserved. No part of this publication may be reproduced or transmitted in any form or by any means, electronic or mechanical, including photocopy, recording, or any information storage or retrieval system, without permission in writing from the copyright holder. 


\title{
Learning rates for energy technologies
}

\author{
Alan McDonald, Leo Schrattenholzer* \\ Environmentally Compatible Energy Strategies Project, International Institute for Applied Systems Analysis (IIASA), \\ Schlossplatz 1 A-2361 Laxenburg, Austria \\ Received 15 July 2000
}

\begin{abstract}
Technological learning, i.e., cost reductions as technology manufacturers accumulate experience, is increasingly being incorporated in models to assess long-term energy strategies and related greenhouse gas emissions. Most of these applications use learning rates based on studies of non-energy technologies, or sparse results from a few energy studies. This report is a step towards a larger empirical basis for choosing learning rates (or learning rate distributions) of energy conversion technologies for energy models. We assemble data on experience accumulation and cost reductions for a number of energy technologies, estimate learning rates for the resulting 26 data sets, analyze their variability, and evaluate their usefulness for applications in long-term energy models. (C) 2001 Elsevier Science Ltd. All rights reserved.
\end{abstract}

For many products and services, unit costs decrease with increasing experience. The idealized pattern describing this kind of technological progress in a regular fashion is referred to as a learning curve, progress curve, experience curve, or learning by doing (Dutton and Thomas, 1984; Argote and Epple, 1990; Argote, 1999). In its most common formulation, unit costs decrease by a constant percentage, called the learning rate, for each doubling of experience.

Because experience accumulates with time, unit costs for a given technology thus decrease with time. Early modeling efforts therefore approximated non-linear learning curves by simple time series in an effort to avoid computational and methodological difficulties. Modelers have specified cost reductions over time both for individual energy technologies (Capros and Vouyoukas, 1999; Nakićenović et al., 1998), and for groups (clusters) of similar technologies (Yohe, 1996; IEA-ETSAP, 1999).

When models in which costs decrease only as a function of time are used to compare alternative greenhouse gas (GHG) emission reduction strategies, they generally favor strategies that delay such reductions (Wigley et al., 1996). This is so because the long-term atmospheric concentration of $\mathrm{CO}_{2}$ depends mainly on cumulative $\mathrm{CO}_{2}$ emissions (Houghton et al., 1996). Thus, for a given

\footnotetext{
* Corresponding author. Tel.: + 43-2236-807225; fax: 43-223671313.

E-mail address: leo@iiasa.ac.at (L. Schrattenholzer).
}

concentration target, it makes no difference whether carbon reductions are early or delayed, and delayed reductions are cheaper. The models therefore tend to recommend delay.

For most products and services, however, it is not the passage of time that leads to cost reductions, but the accumulation of experience. Unlike a fine wine, a technology design that is left on the shelf does not become better the longer it sits unused. Indeed, interruptions in production and use can cause experience to be lost and unit costs to rise, i.e., "forgetting by not doing" in contrast to learning by doing. Therefore, a number of initiatives are underway to incorporate into energy models technological cost reductions, not as functions of time, but as explicit functions of experience, i.e., as learning curves (Messner, 1997; Mattsson, 1997; EIA/DOE, 1999; Goulder and Mathai, 2000; Grübler and Gritsevskii, 2000). Such a formulation introduces in the models both non-linearities and positive feedbacks (the more a technology is used, the greater the incentive for using it more). This drastically increases model complexity and problematic non-convexities, both of which result in large computational requirements. But progress in modeling and computer performance is rapid, and if the new methods are to produce sensible and useful results, good estimates of technological learning rates will be needed as model input.

The importance of good (reliable) learning rate estimates is shown in Fig. 1. Using illustrative, but realistic, 


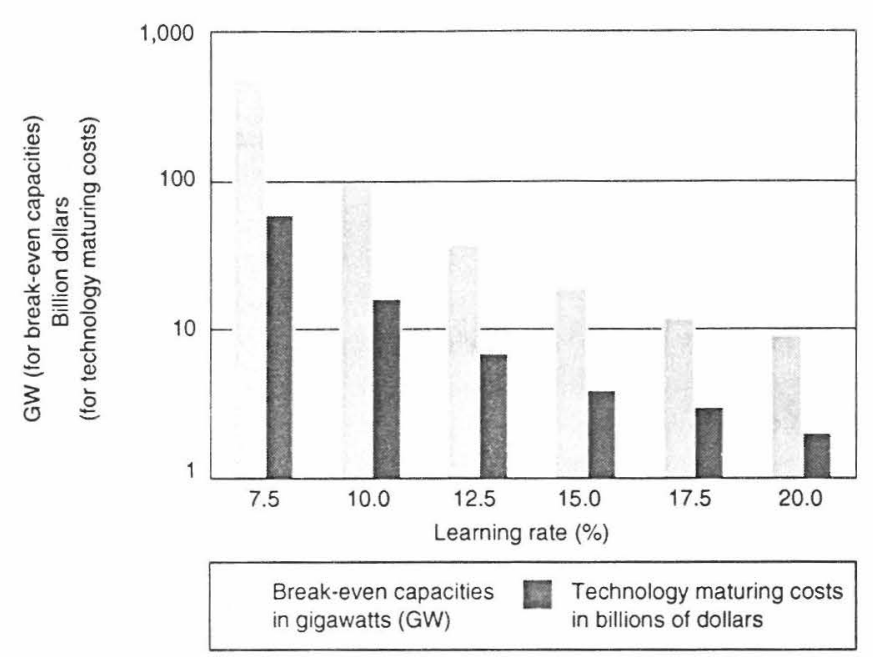

Fig. 1. Sensitivity of break-even capacities and technology maturing costs to learning rate variations.

values, Fig. 1 presents a hypothetical new technology with an initial unit cost of $\$ 2000 \mathrm{~kW}^{-1}$ and a fixed "competitive cost target" of $\$ 1000 \mathrm{~kW}^{-1}$. The left bars represent break-even capacities for a new technology at different assumed learning rates, where the break-even capacity is defined as the capacity additions needed to drive unit costs down to the fixed competitive cost target. The right bars are the technology maturing costs, or the investments - over and above the competitive cost target - needed for the break-even capacity additions. Because the vertical axis of Fig. 1 is logarithmic and the horizontal axis is linear, the figure shows that with decreasing learning rates, technology maturing costs and break-even capacities grow faster than exponentially. For our hypothetical new technology, decreasing the learning rate from 20 to $10 \%$ would increase technology maturing costs from $\$ 2$ billion to $\$ 16$ billion, and the break-even capacity from 9 to $96 \mathrm{GW}$.

Such high, non-linear sensitivity to learning rate variations emphasizes the value of, first, reliable learning rate estimates as inputs and, second, stochastic model formulations that can explicitly calculate the impact of remaining learning rate uncertainties on the eventual model results.

As a step in the direction of reliable estimates of energy-related learning rates, and their uncertainties, this paper assembles data for a variety of energy technologies (from natural gas pipelines to sub-components of end-use technologies), estimates the implied learning rates, checks how well the data fit the classic learning curve model, and draws conclusions about incorporating the resulting learning rates in energy models. Table 1 summarizes 26 data sets and their estimated learning rates assuming that cost reductions are a function only of the experience measure specified in the table. Table 1 also gives the correlation coefficients $\left(R^{2}\right)^{1}$, the measures of technological improvement used in the different cases, and the measures of experience. For comparison, Table 2 lists additional energy-related learning rates that we have collected or calculated from the literature, but for which the original data sets are not available for our own analysis.

The first important feature of Tables 1 and 2 is the range of the estimated learning rates across the energy technologies. The range from Table 1 is illustrated as a histogram in the left panel of Fig. 2. For comparison, the right panel shows the results of Dutton and Thomas' (1984) compilation of over 100 studies of learning rates (not restricted to energy technologies) at the level of individual manufacturing firms. The ranges of learning rates in both panels of Fig. 2 are comparable, and the median value of $16-17 \%$ for energy technologies is not far below the 19-20\% median for the manufacturing firms. This suggests that learning rates (and their variations) from studies not restricted to energy technologies are useful starting points for energy modelers until more detailed studies of energy technologies are available.

To shed light on the reliability of the estimated learning rates, Table 1 also shows the correlation coefficients $\left(R^{2}\right)$ for the estimated learning rates, and the second important feature of the table is the range of values for $R^{2}$. Values range from very good (0.99 for Harmon's data on solar PV modules) to very bad. Moreover, there can be more variability within a given data set than might be suggested by a high $R^{2}$ value. As an example, consider Harmon's data on PV modules as presented in Fig. 3. The left part of the figure fits a learning curve to the data, yielding an estimated learning rate of $20 \%$. The fit looks impressive, and, as just noted, $R^{2}$ equals 0.99 . But on the right of Fig. 3, we still find considerable variety in the data set. This part of the figure shows all learning rates that can be calculated from any two points in the data set, as follows. Consider first the curve labeled "1968" (the first label in the legend box). This curve describes the learning rates between 1968 and the year described by the value on the horizontal axis. Taken together, the curves on the right of Fig. 3 seem to show more variability within the data than is evident from the estimated learning curve on the left, and indicate how much calculated learning rates depend on the data points that are chosen. Given that the bulk of the calculated learning rates with end points in the last 15 years fall between 18 and $25 \%$, the overall learning rate of $20 \%$ shown in Table 1 looks reasonable, but the right-hand side of Fig. 3 suggests an energy modeler might want to incorporate more

\footnotetext{
${ }^{1}$ The correlation coefficient is a real number between 0 and 1 (inclusively). It expresses the quality of the fit between the learning curve model and the data. The extreme values of 0 and 1 reflect "no correlation" (or no explanatory value of the postulated formula) and "perfect correlation" (complete explanation by the postulated formula), respectively.
} 
Table 1

Estimated energy-related learning rates

\begin{tabular}{|c|c|c|c|c|c|c|c|}
\hline Technology & Country/region & Time period & $\begin{array}{l}\text { Estimated } \\
\text { learning rate } \\
(\%)\end{array}$ & $R^{2 \mathrm{~b}}$ & $\begin{array}{l}\text { Performance measure } \\
\text { (dependent variable) }\end{array}$ & $\begin{array}{l}\text { Experience measure } \\
\text { (independent variable) }\end{array}$ & Reference/data source \\
\hline Oil cxtraction & North Seil & & $\approx 25$ & & $\begin{array}{l}\text { sp. labor (man-hrs to } \\
\text { construct one ton of } \\
\text { platform jacket) }\end{array}$ & $\begin{array}{l}\text { cum. cap. (construction } \\
\text { projects) }\end{array}$ & Blackwood (1997) \\
\hline Gas pipelines, onshore & US & $1984-1997$ & 3.7 & 0.09 & sp. inv. price $\left(\$ /\right.$ mile-inch $\left.^{2}\right)$ & cum. cap. (mile-inch ${ }^{2}$ ) & Zhio (1999) \\
\hline Gas pipelines, offshore & US & $1984-1997$ & 24 & 0.76 & sp. inv. price $\left(\$ /\right.$ mile-inch $\left.^{2}\right)$ & cum. cap. (mile-inch $\left.{ }^{2}\right)$ & Zhato (1999) \\
\hline DC converters & World & $1976-1994$ & 37 & 0.35 & conversion losses (\%) & cum. cap. (installed units) & Rabitsch (1999) \\
\hline Gas turbines & World $^{\mathrm{c}}$ & $1958-1963$ & 22 & - & sp. inv. $\cos t(\$ / k W)$ & cum. cap. (MW) & MacGregor et al. (1991) \\
\hline Gas turbines & World ${ }^{\mathrm{C}}$ & $1963-1980$ & 9.9 & - & sp. inv. $\operatorname{cost}(\$ / k W)$ & cum. cap. (MW) & MacGregor et al. (1991) \\
\hline Gas turbines & World $^{\mathrm{C}}$ & $1958-1980$ & 13 & 0.94 & sp. inv. cost $(\$ / k W)$ & cum. cap. (MW) & $\begin{array}{l}\text { Nakićenović et al. (1998); } \\
\text { MacGregor et al. (1991) }\end{array}$ \\
\hline Nuclear power plants & OECD & $1975-1993$ & 5.8 & 0.95 & sp. inv. cost $(\$ / k W)$ & cum. cap. (MW) & Kouvaritakis et al. (2000) \\
\hline Hydropower plants & OECD & $1975-1993$ & 1.4 & 0.89 & sp. inv. cost $(\$ / k W)$ & cum. cap. (MW) & Kouvaritakis et al. (2000) \\
\hline Coal power plants & OECD & $1975-1993$ & 7.6 & 0.90 & sp. inv. $\cos 1(\$ / \mathrm{kW})$ & cum. cap. (MW) & Kouvaritakis et al. (2000) \\
\hline Lignite power plants & OECD & $1975-1992$ & 8.6 & 0.96 & sp. inv. $\cos t(\$ / k W)$ & cum. cap. (MW) & Kouvaritakis et al. (2000) \\
\hline GTCC power plants & OECD & 1984-1994 & 34 & 0.78 & sp. inv. cost $(\$ / k W)$ & cum. cap. (MW) & Kouvaritakis et al. (2000) \\
\hline GTCC power plants & World & $1981-1991$ & $-11^{\mathrm{d}}$ & 0.41 & sp. inv. price $(\$ / k W)$ & cum. cap. (MW) & Claeson (1999) \\
\hline GTCC power plants & World & 1991-1997 & $26^{\mathrm{d}}$ & 0.90 & sp. inv. price $(\$ / \mathrm{kW})$ & cum. cap. (MW) & Claeson (1999) \\
\hline Wind power plants & OECD & $1981-1995$ & 17 & 0.94 & sp. inv. $\cos t(\$ / \mathrm{kW})$ & cum. cap. (MW) & Kouvaritakis et al. (2000) \\
\hline Wind power (electricity) & California & $1980-1994$ & 18 & 0.85 & sp. prod. cost $(\$ / k W h)$ & cum. prod. (TWh) & $\begin{array}{l}\text { CEC (1997); Loiter and } \\
\text { Norberg-Bohm (1999) }\end{array}$ \\
\hline Wind & Germany & $1990-1998$ & 8 & 0.95 & sp. inv. price $(\$ / \mathrm{kW})$ & cum. cap. (MW) & Durstewitz (1999) \\
\hline Wind turbines & Denmark & 1982-1997 & 8 & n.a. & sp. inv. price $(\$ / \mathrm{kW})$ & cum. cap. (MW) & Neij (1999) \\
\hline Solar PV modules ${ }^{\mathrm{e}}$ & World & $1968-1998$ & 20 & 0.99 & sp. inv. price $\left(\$ / \mathrm{W}_{\text {peak }}\right)$ & cum. cap. (MW) & Harmon (2000) \\
\hline Solar PV panels & US & $1959-1974$ & 22 & 0.94 & sp. sale price $\left(\$ / \mathrm{W}_{\text {peak }}\right)$ & cum. cap. (MW) & $\begin{array}{l}\text { Maycock and Wakefield } \\
\text { (1975) }\end{array}$ \\
\hline Ethanol & Brazil & 1979-1995 & 20 & 0.89 & sp. sale price $(\$ /$ boc $)$ & cum. prod. (cubic meters) & Goldemberg (1996) \\
\hline Model-T ford & US & $1909-1918$ & 14 & 0.96 & sale price ( $\$$ per car) & cum. prod. (cars) & $\begin{array}{l}\text { Lipman and Sperling (1999); } \\
\text { Abernathy and Wayne } \\
\text { (1974) }\end{array}$ \\
\hline $\begin{array}{l}\text { Compact fluorescent lamps, } \\
\text { integral-electronic type }\end{array}$ & US & $1992-1998$ & 16 & 0.66 & sp. sale price (\$ per lumen) & cum. prod. (units) & Iwafune (2000) \\
\hline Air conditioners & Japan & 1972-1997 & 10 & 0.82 & sale price (Yen per unit) & cum. sales (units) & Akisawa (2000) \\
\hline $\begin{array}{l}\text { 4-function pocket } \\
\text { calculators }\end{array}$ & US & Early 1970 s & 30 & n. a. & sale price (\$ per unit) & cum. prod. (units) & $\begin{array}{l}\text { Maycock and Wakefield } \\
(1975)\end{array}$ \\
\hline SONY laser diodes & - & 1982-1994 & 23 & 0.95 & prod. cost (Yen per unit) & cum. prod. (units) & Lipman and Sperling (1999) \\
\hline
\end{tabular}

Note: $\mathrm{sp} .=$ specific; inv. $=$ investment; cum. $=$ cumulative; cap. $=$ capacity; prod. $=$ production

"Two cautions are in order concerning values for $R^{2}$. For each line in the table, $R^{2}$ expresses the quality of the fit between the data and the estimated learning curve. However, $R^{2}$ values in different lines should not be compared because sample sizes are different. Second, $R^{2}$ measures the correlation for a straight line fit to the logarithms of the dependent and independent variables. As linear regression minimizes the sum of error squares, this means that relative rather than absolute errors are minimized.

'The geographical scope of the data is not reported explicitly. The context suggests it is the whole world.

¿Note that these learning rates are based on prices, and one explanation of the negative 1981-1991 "learning" rate could be oligopolistic pricing behavior

${ }^{e}$ Based on preliminary data. 
Table 2

Reported energy-related learning rates ${ }^{\mathrm{a}}$

\begin{tabular}{|c|c|c|c|c|c|c|}
\hline Technology & $\begin{array}{l}\text { Country/ } \\
\text { region }\end{array}$ & Time period & $\begin{array}{l}\text { Estimated } \\
\text { learning rate } \\
(\%)\end{array}$ & $\begin{array}{l}\text { Performance measure } \\
\text { (dependent variable) }\end{array}$ & $\begin{array}{l}\text { Experience measure } \\
\text { (independent variable) }\end{array}$ & Reference/data source \\
\hline $\begin{array}{l}\text { Retail gasoline } \\
\text { processing }\end{array}$ & US & $1919-1969$ & 20 & sp. prod. cost $(\$ / b b l)$ & cum. prod. (bbl) & Fisher (1974) \\
\hline Crude oil at the well & US & $1869-1971$ & 5 & sale price $(\$ / \mathrm{bbl})$ & cum. prod. (bbl) & Fisher (1974) \\
\hline $\begin{array}{l}\text { Coal for electric } \\
\text { utilities }\end{array}$ & US & $1948-1969$ & 25 & $\begin{array}{l}\text { sale price to utility } \\
\text { (\$/ton) }\end{array}$ & cum. prod. (tons) & Fisher (1974) \\
\hline $\begin{array}{l}\text { Electric power } \\
\text { production }\end{array}$ & US & $1926-1970$ & 25 & sale price $(\$ / k W h)$ & cum. prod. (kWh) & Fisher (1974) \\
\hline Solar PV & EU & $1985-1995$ & 35 & $\begin{array}{l}\text { sp. prod. cost } \\
(\text { ECU } / \text { kWh })\end{array}$ & cum. prod. (TWh) & IEA (2000) \\
\hline Wind power & US & 1985-1994 & 32 & sp. prod. cost $(\$ / k W h)$ & cum. prod. (TWh) & IEA (2000) \\
\hline Wind power & EU & $1980-1995$ & 18 & sp. prod. cost $(\$ / k W h)$ & cum. prod. (TWh) & IEA (2000) \\
\hline Wind power & Germany & $1990-1998$ & 8 & sp. inv. price $(\$ / \mathrm{kW})$ & cum. cap. (MW) & IEA (2000) \\
\hline Wind power & Denmark & $1982-1997$ & $4^{b}$ & sp. inv. price $(\$ / k W)$ & cum. cap. (MW) & IEA (2000) \\
\hline $\begin{array}{l}\text { Electricity from } \\
\text { biomass }\end{array}$ & $\mathrm{EU}$ & $1980-1995$ & 15 & sp. prod. cost $(\$ / k W h)$ & cum. prod. (TWh) & IEA (2000) \\
\hline Supercritical coal & US & n.a. & 3 & sp. prod. cost $(\$ / k W h)$ & cum. prod. (TWh) & $\begin{array}{l}\text { IEA (2000); Joskow and } \\
\text { Rose (1985) }\end{array}$ \\
\hline GTCC & EU & n.a. & 4 & sp. prod. cost $(\$ / k W h)$ & cum. prod. (TWh) & $\begin{array}{l}\text { IEA (2000); Claeson } \\
(1999)\end{array}$ \\
\hline Solar PV modules & World & $1976-1992$ & 18 & sale price $\left(\$ / W_{\text {peak }}\right)$ & cum. sales (MW) & IEA $(2000)$ \\
\hline Solar PV modules & EU & $1976-1996$ & $21^{\mathrm{c}}$ & sale price $\left(\$ / \mathrm{W}_{\text {peak }}\right)$ & cum. sales (MW) & IEA (2000) \\
\hline Ethanol & Brazil & $1978-1995$ & $22^{\mathrm{d}}$ & sp. sales price $(\$ /$ boe $)$ & $\begin{array}{l}\text { cum. prod. (cubic } \\
\text { meters) }\end{array}$ & IEA (2000) \\
\hline Coal power plants & US & $1960-1980$ & $1.0-6.4^{\mathrm{e}}$ & sp. inv. cost $(\$ / \mathrm{kW})$ & cum. cap. (units) & Joskow and Rose (1985) \\
\hline
\end{tabular}

${ }^{\mathrm{a}}$ Note: $\mathrm{sp} .=$ specific; inv. $=$ investment; cum. = cumulative; cap. = capacity; prod. = production.

${ }^{b}$ Based on Neij (1999). The learning rate of $4 \%$ considers only wind turbines equivalent to $55 \mathrm{~kW}$ or larger. The $8 \%$ learning rate reported in Table 1 for Neij's data includes all Danish wind turbines.

" $21 \%$ is the learning rate for the "stability" stage described in the text. For the "development" and "price umbrella" stages the learning rate is $16 \%$. For the "shakeout" stage it is $47 \%$.

d $22 \%$ is the learning rate for the "stability" stage described in the text. For the "development" and "price umbrella" stages the learning rate is $10 \%$. For the "shakeout" stage it is $53 \%$.

"Joskow and Rose estimate a range of learning rates for different utilities, architect-engineering firms, and technology categories, after accounting for inflation, plant size, the inclusion of scrubbers or cooling towers, whether certain structures are indoors or out, and whether a unit is the first on a site.
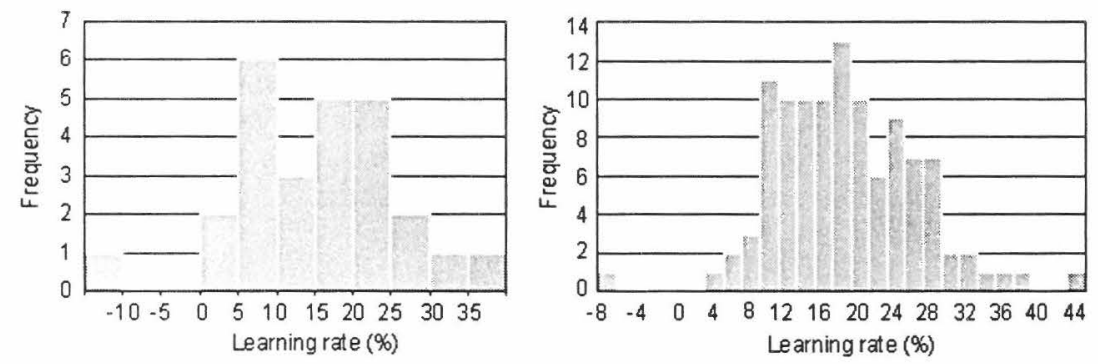

Fig. 2. Distribution of learning rates in Table 1 (left panel) and as observed in 22 field studies (right panel) (Dutton and Thomas, 1984).

uncertainty about this value than suggested simply by the $R^{2}$ value of 0.99 .

The frequent occurrence of low values for $R^{2}$ in Table 1 means that further research is needed to discover missing explanatory factors, some (but not all) of which may be important to include in long-term energy models. As an example of such additional information, consider the one negative "learning" rate in Table $1,-11 \%$ for gas turbine combined-cycle (GTCC) power plants from Claeson's 1981-1991 data. Note first that the dependent variable for this data set is the specific investment price, not cost. Prices are driven by many factors besides costs, and are for that reason inferior to costs as measures of learning and technological progress. In this case in particular, one 

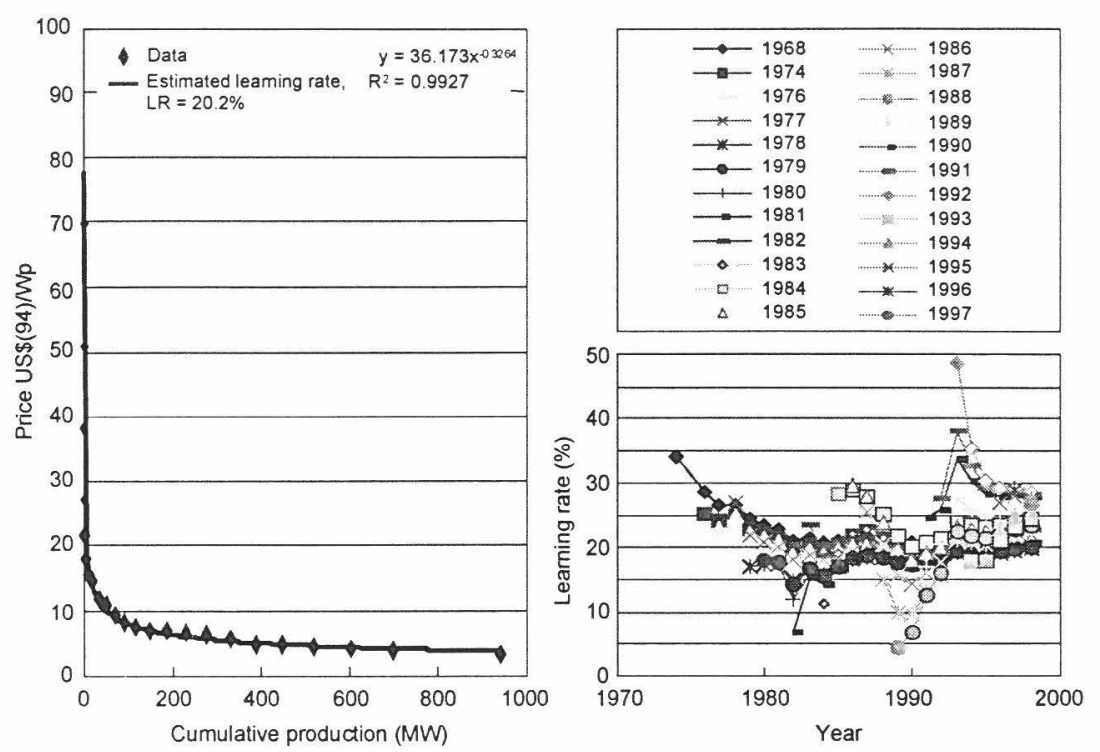

Fig. 3. Learning curve estimated for Harmon's data (2000) on unit prices for solar PV modules (left panel) and variability in learning rates (right panel).

possible explanation of the negative learning rate is short-term oligopolistic pricing behavior (Claeson, 1999). To the extent that such behavior explains the negative learning rate for this data set, the calculated learning rate is largely irrelevant for long-term global energy scenarios in which costs rather than prices are the relevant variable. Another explanatory factor is suggested by the negative learning rate shown in the right panel of Fig. 2, which describes the production experience of Lockheed's L1011 TriStar and provides good evidence of experience depreciation. Experience depreciation is much more relevant to long-term energy scenarios than short-term oligopolistic pricing behavior. It should thus be given higher priority in subsequent research to quantify the missing explanatory factors indicated by low $R^{2}$ values in Table 1.

We now turn to the third important feature of Table 1, variations in learning rates among and within data sets for the same technology. Two cases are evident in the table, gas turbines and GTCC power plants. If we neglect the GTCC data set with the negative learning rate (for the reasons discussed in the last paragraph), the trend seems to be that later data imply lower learning rates. Some energy modeling groups therefore use "kinked" (piece-wise linear) learning curves, with successively lower learning rates for technologies at more mature development stages (Kouvaritakis et al., 2000). ${ }^{2}$ In an alternative formulation, used by Argote (1999) and

\footnotetext{
${ }^{2}$ We refer here to kinks in learning curves for costs. Such kinks reflect postulated decreases in learning rates as technologies mature. This is different from proposed kinks in learning curves for prices to reflect changing relationships between cost and price learning rates as markets mature (see discussion of the IEA/BCG model).
}

others, experience depreciates with time, i.e., experience gained from units built last year results in greater current cost reductions than experience from 10 years ago. This formulation results in the same phenomenon of decreasing learning rates, but in a smooth fashion, not requiring largely arbitrary boundaries between different development stages. Both Argote's and the "kinked" approaches can lead to learning "floors", i.e., non-zero minimums below which unit costs will never fall.

To evaluate and enhance the usefulness of the estimates in Table 1 we need to summarize additional information, provided by the original sources, that might have potentially misleading impacts on learning rate estimates. First, as noted above, prices can be very imperfect measures of costs, and for a number of entries in Table 1, it is price that is the dependent variable. Goldemberg's ethanol data (1996), for example, are in terms of the price paid ethanol producers in Brazil, and a closer look at his original data suggests that these prices have to some extent moved up and down with international oil prices. Thus, some of the variability in Goldemberg's data reflects not variability in ethanol production costs, but volatility in the international oil markets. In this light, estimated learning rate of $20 \%$, as in Table 1, appears more reliable than indicated by the associated $R^{2}$ value of 0.89 . Neij, who also analyzes prices, finds indications in her data of wind-turbine manufacturers selling below cost to drive out competitors (Neij, 1999). If this is indeed the case, her price data should underestimate costs nearer the beginning of her data set and overestimate costs near the end (presuming less competition after some competitors have left the market). In that case, the learning rate of $8 \%$, estimated from her data in Table 1, would appear to be too low. 
The International Energy Agency (IEA) offers a general extended model of relationships between costs and prices based on prior work by the Boston Consulting Group (BCG) (IEA, 2000). The qualitative background of the model is the assumption that costs decrease at a constant learning rate, but price reductions can be divided into four stages. In the first two stages ("development" and "price umbrella"), the learning rate in terms of prices is constant but lower than the constant learning rate for costs. In the "shakeout" stage the learning rate for prices is higher than that for costs. And in the "stability" stage, learning rates for prices and costs are identical. This model is consistent both with Goldemberg's data cited above (see Table 2) and with Neij's data. Her estimated $8 \%$ learning rate is close to the $10 \%$ the IEA considers typical for the "development" (and "price umbrella") stage. It can also help explain Akisawa's study (2000) of prices for new "heat-pump" air conditioners. He noted particular price volatility around the time the new technology was most aggressively displacing conventional air conditioners. Calculations based only on data from after the period of price volatility yield both a higher learning rate $(17 \%)$ and higher correlation coefficient $(0.94)$ than the data set as a whole. Postulating that the post-volatility period corresponds to the stability stage of the IEA/BCG model, a learning rate of $17 \%$ would be more appropriate in long-term energy models than the 10\% shown in Table 1 for the whole data set.

In addition to experience depreciation and short-term pricing behavior, other possible causes of variability or biases in Table 1 include:

- differences in performance measures (e.g., investment costs vs. production costs) or in experience measures (e.g., cumulative capacity or cumulative production),

- definitional differences (are the costs of land acquisition, pollution abatement, and interest during construction treated uniformly for all entries in a data set?),

- varying intensities of research and development (R\&D),

- economies of scale,

- and cost variability for such things as land costs, wages, and interest payments that are driven by property, financial, and labor markets.

At this stage we can say something about differences in performance and experience measures and about economies of scale, but not much about the other factors. (An important focus of future research, however, will be the interplay between learning rates and $R \& D$, given the pressure on governments to increase energy $R \& D$ expenditures.) Concerning different performance and experience measures, we expect learning rates calculated using production costs and cumulative production to be higher than those using investment costs and cumulative capacity if there are concurrent increases in load factors. This is especially true if fuel costs are low - n.b., the variations in learning rates for wind in Tables 1 and $2 .^{3}$ Concerning economies of scale, the learning rate in the last row of Table 2 for coal-fired power plants is calculated from a regression that includes a scale term. Thus, it reflects learning after any economies of scale have been taken into account. This is not the case for the other power plant data presented here. They almost certainly include some scale effects, which may partially explain why they yield generally higher learning rates than the last row of Table 2. For long-term energy modeling, however, it is not clear how much effort should be put into trying to distinguish between the two factors. Given the data that are available, model inputs in which learning and scale economies are lumped into a single estimated learning rate may be simpler, as reliable, and therefore more useful than efforts to extract the two separate effects from the empirical data, and then treat them separately in long-term energy models.

The purpose of the analysis presented here was to expand the empirical basis for the choice of learning rates and uncertainty ranges used in long-term energy models. We have presented a first edition of a catalogue of energy-related learning rates intended to quantify the phenomenon of experience-related cost reductions at a level useful to energy modelers. Analyzing the quality of the statistically estimated learning rates we conclude that some of the identified causes of data variability, such as price swings due to marketing strategies, can be considered random and inconsequential for long-term energy models. More work is necessary, however, to properly address other factors, particularly experience depreciation and the impact of R\&D investments.

\section{References}

Abernathy, W.J., Wayne, K., 1974. Limits of the learning curve. Harvard Business Review 52, 5.

Akisawa, A., 2000. Technological development and market substitution of heat pumps - a case of room air-conditioners in Japan, unpublished data.

Argote, L., 1999. Organizational Learning: Creating, Retaining and Transferring Knowledge. Kluwer, Dordrecht, Netherlands.

Argote, L., Epple, D., 1990. Learning curves in manufacturing. Science $247,920$.

Blackwood, D., 1997. Eastern Trough Area Project (ETAP), Engineer, June, p. 4.

\footnotetext{
${ }^{3}$ For wind power IEA's data show higher learning rates when using production costs and experience than when using investment costs and cumulative capacity. This they attribute partly to increasing load factors. They also attribute the difference in learning rates, depicted in Table 2, for the EU and the US partly to faster load factor learning in the US. But this still leaves unexplained the difference between the US learning rate in Table $2(32 \%)$ and the California learning rate in Table $1(18 \%)$.
} 
Capros, P., Vouyoukas, E.L. (Eds.), 1999. Energy Technology Dynamics and Advanced Energy System Modelling, Report of the TEEM Project (EC Contract JOS3-CT97 0013).

CEC (California Energy Commission), 1997. Wind Project Performance, 1995 Summary Staff Report, June.

Claeson, U., 1999. Experience curves for policy making - the case of energy technologies. Proceedings of the IEA International Workshop, Stuttgart, Germany, 10-11 May 1999.

Durstewitz, M., 1999. Experience curves for policy making: the case of energy technologies. Paper presented at IEA International Workshop, Stuttgart, Germany, 10-11 May.

Dutton, J.M., Thomas, A., 1984. Treating progress functions as a managerial opportunity. Academy of Management Review 9, 235.

EIA/DOE, 1999. Department of Energy, Washington, DC (EIA/DOE$0607(99))$.

Fisher, J.C., 1974. Energy Crises in Perspective. Wiley, New York, USA.

Goldemberg, J., 1996. Energy Policy 24, 1127.

Goulder, L.H., Mathai, K., 2000. Optimal $\mathrm{CO}_{2}$ abatement in the presence of induced technological change. Journal of Environmental Economics and Management 39, 1.

Grübler, A., Gritsevskii, A., 2000. A model of endogenous technological change through uncertain returns on innovation. Ukrainian Economic Review 6.

Harmon, C., 2000. Experience Curves of Photovoltaic Technology, IR 00-014, IIASA, Laxenburg, Austria.

Houghton, J.T., 1996. Climate change 1995. The Science of Climate Change. Cambridge University Press. Cambridge, UK.

IEA, 2000. Experience Curves for Energy Technology Policy. International Energy Agency, Paris, France (ISBN 92-64-17650-0).

IEA-ETSAP, 1999. The MARKAL energy system model(http://www. ecn.nl/unit_bs/etsap/markal/main.html), Frequently asked questions (http://www.ecn.nl/unit_bs/etsap/markal/main.html).

Iwafune, Y., 2000. Technology Progress Dynamics of Compact Fluorescent Lamps, IR-00-009, IIASA, Laxenburg, Austria.

Joskow, P.L., Rose, N.L., 1985. The effects of technological change, experience, and environmental regulation on the construction cost of coal-burning generating units. Rand Journal of Economics 16, 1.
Kouvaritakis, N., Soria, A., Isoard, S., 2000. Modelling energy technology dynamics: methodology for adaptive expectations models with learning by doing and learning by searching. International Journal of Global Energy Issues 14, 1-4.

Lipman, T.E., Sperling, D., 1999. Experience curves for policy making: the case of energy technologies. Paper presented at IEA International Workshop, Stuttgart, Germany, 10-11 May.

Loiter, J.M., Norberg-Bohm, V., 1999. Technology policy and renewable energy: public roles in the development of new energy technologies. Energy Policy 27, 85.

MacGregor, P.R., Maslak, C.E., Stoll, H.G., 1991. The Market Outlook for Integrated Gasification Combined Cycle Technology. General Electric Company, New York.

Mattsson, N., 1997. Internalizing technological development in energy systems models. Thesis for the Degree of Licentiate of Engineering, Chalmers University of Technology, Göteborg, Sweden.

Maycock, P.D., Wakefield, G.F., 1975. Business Analysis of Solar Photovoltaic Energy Conversion. Texas Instruments Incorporated, Dallas, TX.

Messner, S., 1997. Endogenized technological learning in an energy systems model. Research Report RR 97-15, IIASA, Laxenburg, Austria.

Nakičenović, N., Grübler, A., McDonald, A. (Eds.), 1998. Global Energy Perspectives. Cambridge University Press, Cambridge, UK.

Neij, L., 1999. Experience Curves for Wind Turbines. Energy - The International Journal 24, 5.

Rabitsch, H., 1999. Electricity transmission networks in Eurasia, unpublished data.

Wigley, T.R., Richels, R., Edmonds, J., 1996. Economic and environmental choices in the stabilization of atmospheric $\mathrm{CO}_{2}$ concentrations. Nature 359, 240.

Yohe, G., 1996. Exercises in hedging against extreme consequences of global change and the expected value of information. Global Environmental Change 6, 2.

Zhao, J., 1999. The diffusion and costs of natural gas infrastructures, unpublished data 



\section{Ordering Information}

Orders must include the publication number and should be sent to the Publications Department, International Institute for Applied Systems Analysis, A-2361 Laxenburg, Austria.

Telephone: +432236807

Telefax: +43223671313

E-mail:molina@iiasa.ac.at

A full list of IIASA publications is available at www.iiasa.ac.at 
International institute for Applied Systems Analysis

$\Rightarrow$ Tel: +432236807 Fax: +43223671313

IIASA nuw.iiasa.ac.at 